\title{
DISTRIBUIÇÃO E BIODISPONIBILIDADE DE CRÔMIO EM SOLOS CONTAMINADOS POR RESÍDUOS DE COURO
}

Ademir dos Santos*, Luciana Camargo de Oliveira, Wander Gustavo Botero André dos Santos e Julio Cesar Rocha

Instituto de Química de Araraquara, Universidade Estadual Paulista, CP 355, 14800-900 Araraquara - SP, Brasil

Maria Lúcia Ribeiro

Centro Universitário de Araraquara, R. Voluntários da Pátria, 14800-900 Araraquara - SP, Brasil

Alessandro Silva de Oliveira

Fundação Instituto de Terras do Estado de São Paulo, Av. Paraná, 114, 14811-124 Araraquara - SP, Brasil

Recebido em 11/2/08; aceito em 13/4/09; publicado na web em 26/8/09

\begin{abstract}
DISTRIBUTION AND BIOAVAILABILITY OF CHROMIUM IN CONTAMINATED SOILS BY TANNERY RESIDUES. Samples of soil, water and sediment were collected and analyzed in order to evaluate chromium contamination due to deposition of tannery residues onto soils under different management regimes. The results showed that soils used for sugar cane cultivation were not adversely impacted. However, in the case of mango plantations, variable concentrations of chromium were measured in the soil profile, with $22.2 \%$ of values being higher than permitted legal limits, and $38.9 \%$ being at levels requiring remediation. Concentrations of bioavailable chromium were lower than the detection limit of the method $\left(0.01 \mathrm{mg}\right.$ of chromium $\mathrm{kg}^{-1}$ of soil), indicating that all of the chromium present in the samples was either complexed or in an insoluble form. Chromium concentrations measured in samples of water and sediments were indicative of low mobility of the metal in soils. The main cause of differences found between soil samples obtained from different cultivations was the type of soil management.
\end{abstract}

Keywords: environmental contamination; tannery residues; chromium.

\section{INTRODUÇÃO}

A contaminação ambiental por metais potencialmente tóxicos tem sido objeto de vários estudos, devido à sua elevada aplicabilidade e toxicidade. ${ }^{1,2}$ Entre os metais mais usados no setor industrial destacase o crômio, empregado na fabricação de aço inoxidável, pigmentos, cerâmica, borracha, fitas magnéticas e em curtumes. ${ }^{1,2}$ No processamento do couro a etapa de curtição é fundamental e consiste na reação de espécies químicas, como o crômio, com proteínas, ocorrendo a transformação do colágeno da pele em couro pelo entrelaçamento das protofibrilas do colágeno. ${ }^{3}$ Os couros obtidos pelo curtimento com crômio caracterizam-se por elevada estabilidade hidrotérmica, maior flexibilidade e resistência, características desejadas pelo mercado consumidor. ${ }^{1}$

$\mathrm{O}$ crômio possui diferentes estados de oxidação $\mathrm{Cr}$ (II), $\mathrm{Cr}$ (III), $\mathrm{Cr}(\mathrm{IV}), \mathrm{Cr}(\mathrm{V})$ e $\mathrm{Cr}(\mathrm{VI})$, sendo as formas mais estáveis $\mathrm{Cr}(\mathrm{III})$ e $\mathrm{Cr}(\mathrm{VI})$ e sua toxicidade depende do estado de oxidação. O crômio(III) é um elemento essencial à nutrição humana e sua deficiência provoca distúrbios relacionados ao metabolismo da glicose, uma vez que age como potencializador da insulina. Entretanto, em elevadas concentrações no organismo, o Cr(III) pode ser responsável pela inibição de diferentes processos celulares. ${ }^{4} \mathrm{O} \mathrm{Cr}(\mathrm{VI})$ é tóxico para o organismo humano devido a seu elevado potencial de oxidação e capacidade para atravessar membranas biológicas, sendo classificado como carcinogênico classe A. ${ }^{5}$ Reações de óxido-redução modificando os estados de oxidação do crômio podem ocorrer naturalmente no ambiente, embora a forma hexavalente, em geral, se apresente em menor concentração.

Em solos, as formas mais estáveis do crômio são Cr(III) e Cr(VI), mas em algumas plantas $\mathrm{Cr}(\mathrm{V})$ foi determinado como produto inter-

*e-mail: ademir@iq.unesp.br

"Universidade Federal de Alagoas, Campus de Arapirara, CP 61, 57309-005

Arapirara - AL, Brasil mediário da redução de $\mathrm{Cr}(\mathrm{VI}) .{ }^{6}$ Ferreira et $a l .{ }^{7}$ avaliaram o efeito da adição de resíduos de curtume sobre solo e plantas cultivadas em Argissolo Vermelho. A adição de lodo de curtume aumentou o pH, o teor de cálcio trocável e não foram constatadas alterações nas concentrações dos metais $\mathrm{Cu}, \mathrm{Cd}, \mathrm{Pb}$ e $\mathrm{Ni}$ no solo. Entretanto, os teores de $\mathrm{Cr}$ aumentaram significativamente. A adição de serragem cromada, resíduo sólido gerado do processamento de peles em curtumes, não influenciou no rendimento dos grãos das culturas de soja e milho e tanto as adições de lodo de curtume como a de serragem cromada estimularam a atividade microbiana do solo. Castilhos e colaboradores $^{8}$ avaliaram efeitos de doses crescentes de Cr(VI) em culturas de soja, verificando a diminuição na fixação biológica de nitrogênio e na absorção de nutrientes como fósforo, potássio, cálcio e magnésio, essenciais para o desenvolvimento das plantas. Compostos hexavalentes de crômio (principalmente cromatos e dicromatos) possuem maior mobilidade nos solos do que compostos contendo crômio trivalente.

Estudos de oxidação e redução do crômio em amostras ambientais têm sido descritos na literatura. Han et $_{\text {al. }}{ }^{2}$ investigaram a distribuição, transformação e biodisponibilidade de crômio trivalente e hexavalente em solos contaminados. Os resultados do estudo mostraram a importante função da matéria orgânica na ligação do $\mathrm{Cr}$ adicionado, independentemente do estado de oxidação do metal.

A contaminação mundial de crômio em solos surgiu da prática comum do descarte de resíduos de curtume sob a suposição que a espécie dominante nestes resíduos devem ser espécies de $\mathrm{Cr}$ (III), termodinamicamente estáveis. ${ }^{9}$ Entretanto, níveis significativos de $\mathrm{Cr}(\mathrm{VI})$ foram recentemente detectados em águas superficiais e subterrâneas na Índia, China e Austrália. Isso ocorre, possivelmente, devido à presença natural de minerais nos solos, principalmente óxido de manganês, oxidando $\mathrm{Cr}$ (III) a Cr(VI). Em pH elevado, $\mathrm{Cr}$ (VI) está biodisponível e é a forma de maior mobilidade, apresentando risco de contaminação de águas subterrâneas.

Alcântara e Camargo, ${ }^{1}$ estudando a lixiviação de Cr(III) em colunas de solos, verificaram que o tipo de solo, o horizonte e a fonte 
de crômio influenciam na sua mobilidade. Segundo estes autores, a eluviação do crômio foi maior no horizonte com maior teor de ácido fúlvico, possivelmente em decorrência da formação de compostos solúveis de crômio complexado com ácido fúlvico. Passianoto e colaboradores, ${ }^{10}$ estudando os efeitos da aplicação de dois lodos de curtume (lodo do caleiro e lodo com crômio) em solos, verificaram aumento na atividade e da biomassa microbiana, e a dose máxima de crômio trivalente não causou danos à fauna microbiana.

O efeito da sazonalidade na especiação do crômio, transformações e solubilidade foi investigado utilizando solos de várzea do vale do Mississipi e colunas inundadas. Os resultados mostraram que o potencial redox foi determinante na capacidade do solo em absorver e reter o crômio. Os solos estudados atuam como sorvedouro para crômio diminuindo a contaminação em ecossistemas aquáticos. ${ }^{11}$ Entretanto, os autores ressaltam que estes resultados são dependentes da composição do solo. James e Bartlett ${ }^{12}$ simularam a disposição de resíduos orgânicos contendo $\mathrm{Cr}$ (III) no solo, verificando que complexos orgânicos modificam a solubilidade do crômio. Os resultados indicaram que se o $\mathrm{Cr}$ (III) complexado a compostos orgânicos presentes nos resíduos for adicionado ao solo poderá lixiviar e contaminar aquíferos subterrâneos.

Estas investigações são importantes para avaliação de risco, pois demonstram que ao dispor resíduos sólidos contendo espécies de crômio, dependendo da composição do solo, poderá ocorrer contaminação dos sistemas aquáticos.

No Estado de São Paulo, estão estabelecidos procedimentos, critérios e padrões para a proteção da qualidade do ar, das águas superficiais, assim como critérios e normas para controle da poluição por resíduos sólidos. Ainda não ocorre o mesmo para solos e águas subterrâneas. A Companhia de Tecnologia de Saneamento Ambiental (CETESB), de acordo com a legislação vigente no Estado (Decretos $n^{\circ} 8468 / 76$ e n ${ }^{\circ} 32955 / 91$ ), tem a atribuição de prevenir e controlar a poluição dos solos e águas subterrâneas e para tal propósito adota valores orientadores para diferentes substâncias. No caso do crômio os valores orientadores (Tabela 1) variam de $40 \mathrm{mg} \mathrm{kg}^{-1}$ de solo (referência de qualidade) a $400 \mathrm{mg} \mathrm{kg}^{-1}$ de solo (intervenção industrial). ${ }^{13}$

Tabela 1. Valores orientadores de crômio para solos ${ }^{13}$

\begin{tabular}{lcc}
\hline $\begin{array}{l}\text { Referência de qualidade } \\
\left(\mathrm{mg} \mathrm{kg}^{-1} \text { de solo }\right)\end{array}$ & $\begin{array}{c}\text { Prevenção } \\
\left(\mathrm{mg} \mathrm{kg}^{-1} \text { de solo }\right)\end{array}$ & $\begin{array}{c}\text { Intervenção agrícola } \\
\left(\mathrm{mg} \mathrm{kg}^{-1} \text { de solo }\right)\end{array}$ \\
\hline 40 & 75 & 150 \\
\hline
\end{tabular}

Em 2001, aproximadamente 150 toneladas de resíduos de couro foram incorporadas ao solo como fonte de matéria orgânica no assentamento Monte Alegre localizado nas cidades de Araraquara, Motuca e Matão (área de aproximadamente 3200 hectares), Bacia hidrográfica do Mogi-Guaçu (URGH 9)..$^{14,15}$

Nessa região, existem várias indústrias que manufaturam o couro para produção de luvas utilizadas para diversos fins e, principalmente, por trabalhadores rurais no corte da cana, cultura que predomina no sudeste do estado de São Paulo. Sem destino certo, os resíduos de aparas de couro da fabricação das luvas foram descartados sem controle e sem preocupação quanto a possíveis contaminações. De acordo com relatório CETESB,${ }^{14}$ o descarte irregular provocou a contaminação de lotes no assentamento, via decomposição/lixiviação dos resíduos contendo íons crômio para solos, nos quais são cultivadas espécies, tais como cana-de-açúcar e manga. ${ }^{14,15}$

Considerando este impacto ambiental, investigou-se neste trabalho a distribuição e (bio)disponibilidade de crômio em solos, águas e sedimentos do assentamento Monte Alegre, onde foram descartados, há 6 anos, resíduos de aparas de couro.

\section{PARTE EXPERIMENTAL}

\section{Reagentes}

Utilizaram-se reagentes com grau e pureza analítica e as soluções foram preparadas com água desionizada (sistema Milli-Q, Millipore).

\section{Planejamento de amostragem}

Para avaliar a distribuição e biodisponibilidade do crômio, amostras de solo, sedimento e água superficial foram coletadas nos lotes que apresentaram, em 2002, elevada concentração de crômio. ${ }^{14,15}$

\section{Coleta das amostras de solos}

O local de amostragem está situado na região de Araraquara-SP pertencente à Bacia Mogi-Guaçu (Figura 1). As amostras de solos foram coletadas utilizando trincheiras abertas com cavadeiras em locais de cultivos de cana e de manga nas profundidades de 0-5, 5-10, 10-20, 20-40, 40-60 cm e 1 m. Os sítios (cana-de-açúcar e manga) foram divididos individualmente em 3 pontos de amostragens equidistantes aproximadamente $25 \mathrm{~m}$, em linha reta. Em cada um desses pontos foram coletadas três amostras simples nas 6 diferentes profundidades. Amostras testemunho foram coletadas em locais de cultivo de mandioca, onde não foram descartadas aparas de couro, obedecendo ao mesmo procedimento.

Após mistura e homogeneização das amostras simples, foram retirados cerca de $500 \mathrm{~g}$ de cada mistura, constituindo as respectivas amostras compostas A-C.

Com o objetivo de verificar a distribuição do crômio na superfície do solo, 10 amostras de solos, de diferentes cultivos, foram coletadas distanciadas $50 \mathrm{~m}$ uma da outra e na profundidade de $0-5 \mathrm{~cm}$.

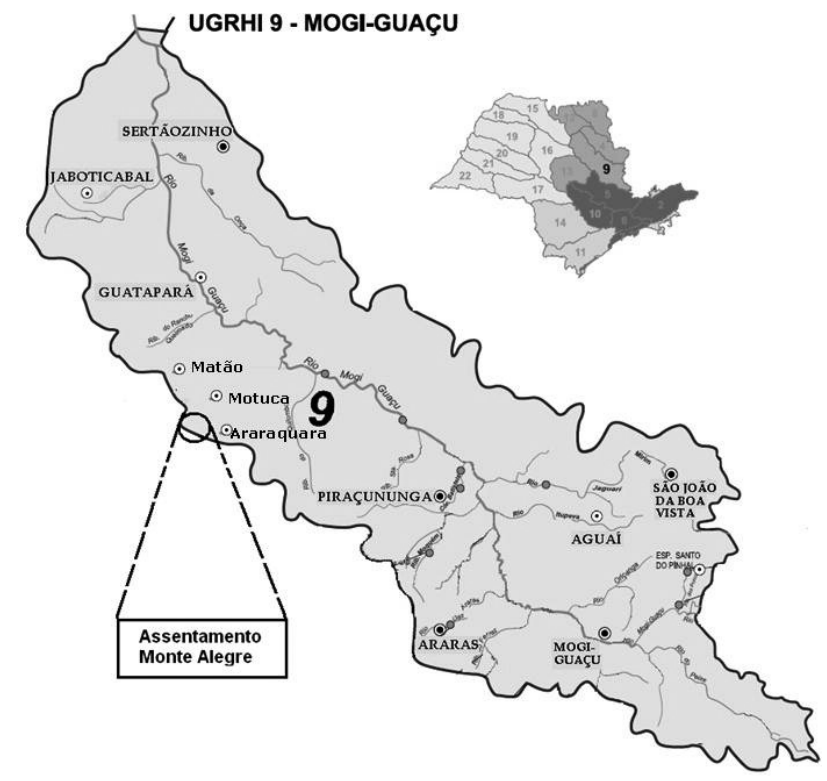

Figura 1. Local de amostragem, situado na região de Araraquara-SP, pertencente à Bacia Mogi-Guaçu

\section{Preparo das amostras de solo}

As amostras de solos foram transferidas para bandejas de madeira. Após tratamento preliminar (secagem ao ar, desagregação e peneiramento a $2 \mathrm{~mm}$ ) as amostras foram submetidas à digestão ácida para determinações dos metais totais e potencialmente biodisponíveis. 


\section{Coleta das amostras de água superficial}

Amostras de águas foram coletadas no córrego que atravessa o assentamento e recebe por lixiviação laminar material proveniente dos cultivos de manga, cana-de-açúcar e mandioca. Um litro de água a montante e outro a jusante foram coletados a $30 \mathrm{~cm}$ da superfície diretamente em frascos de polietileno. Estes frascos foram previamente descontaminados no laboratório, em banho de solução de ácido nítrico diluído e no local de amostragem foram lavados consecutivamente 3 vezes com água do próprio córrego.

\section{Coleta das amostras de sedimento}

Duas amostras de sedimentos foram coletadas a montante e a jusante utilizando draga de Petersen, de acordo com as recomendações feitas por Mozeto et al. ${ }^{16}$ As amostras foram secas ao ar, desagregadas e peneiradas a $2 \mathrm{~mm}$.

\section{Determinação dos teores de matéria orgânica em solo}

Os teores de matéria orgânica foram determinados pelo método Walkley e Black adaptado. ${ }^{17}$

\section{Digestão das amostras de solo e determinação de crômio total}

O processo de digestão das amostras foi feito em triplicata, segundo método da EPA previamente adaptado. ${ }^{18} \mathrm{Em}$ aproximadamente $2,00 \mathrm{~g}$ de amostra foram adicionados $10,0 \mathrm{~mL}$ de água desionizada e 10,0 mL de solução de ácido nítrico concentrado, aquecendo-se a mistura a $120^{\circ} \mathrm{C}$ (em ebulição) por $20 \mathrm{~min}$. As determinações de crômio foram feitas por espectrometria de absorção atômica com atomização por chama. A validação das determinações foi feita utilizando material certificado de solo San Joaquin soil SRM 2709 EUA com concentração certificada de $130 \pm 4 \mu \mathrm{g} \mathrm{g}^{-1}$.

\section{Tratamento de amostras de solo para determinação de $\mathbf{C r}$ potencialmente biodisponível}

Transferiram-se 2,50 g de amostra seca para frasco de $100 \mathrm{~mL}$ e adicionaram-se 50,0 mL de solução de ácido clorídrico $0,10 \mathrm{~mol}$ $\mathrm{L}^{-1}$. Agitou-se a suspensão por $2 \mathrm{~h}$ à temperatura ambiente em mesa agitadora de movimento circular horizontal com rotação de $200 \mathrm{rpm}$. Após repouso para decantação do material sólido, filtrou-se em papel Whatman 42, transferiu-se o filtrado para frasco de vidro e estocou-se a $4{ }^{\circ} \mathrm{C}$. As determinações de crômio foram feitas por espectrometria de emissão atômica com plasma de argônio induzido (ICP OES), Thermo Jarrel Ash, modelo: IRIS/AP. ${ }^{19}$

\section{Digestão das amostras de água para determinação de Cr total}

Transferiram-se $100,00 \mathrm{~mL}$ de amostra para tubo de digestão acondicionado em bloco digestor. Adicionaram-se $15,0 \mathrm{~mL}$ de solução de ácido nítrico concentrado e, sob aquecimento de $150{ }^{\circ} \mathrm{C}$, evaporou-se até $50 \mathrm{~mL}$. Após adição de $1,0 \mathrm{~mL}$ de solução de peróxido de hidrogênio $30 \%$ (v/v) a amostra foi deixada sob refluxo até final da digestão utilizando-se funil de haste curva como tampa para os tubos. ${ }^{20}$ Transferiu-se o extrato para balão volumétrico de $100,00 \mathrm{~mL}$ e completou-se o volume com água.

\section{Determinação de $\operatorname{Cr}($ VI) em amostras de água}

Em 50,0 mL de amostra, adicionou-se cloreto de amônio e aqueceu-se à $80{ }^{\circ} \mathrm{C}$ por $5 \mathrm{~min}$. Filtrou-se a solução e ajustou-se o
pH com ácido sulfúrico $\left(0,5 \mathrm{~mol} \mathrm{~L}^{-1}\right)$ entre 4-5. Posteriormente, determinou-se $\mathrm{Cr}(\mathrm{VI})$ utilizando-se o método espectrofotométrico da 1,5 - difenilcarbazida (DPC). ${ }^{21}$

\section{Digestão das amostras de sedimento para determinação de Cr total}

Transferiram-se 2,00 g de amostra para tubo de digestão, adicionaram-se $10,0 \mathrm{~mL}$ de água oxigenada e deixou-se em repouso por 12 h. Posteriormente, adicionou-se solução de ácido nítrico concentrado aquecendo-se a mistura por aproximadamente $120{ }^{\circ} \mathrm{C}$ até digestão completa da matéria orgânica (extrato límpido e material insolúvel). Os extratos foram transferidos para balão volumétrico de $100,0 \mathrm{~mL}$ e a leitura foi feita por espectrometria de emissão atômica com plasma de argônio induzido (ICP OES), Thermo Jarrel Ash, modelo IRIS/AP. ${ }^{18} \mathrm{~A}$ validação das determinações foi feita utilizando material certificado de sedimento SRM 1646a com concentração certificada de 40,9 $\pm 1,9 \mu \mathrm{g} \mathrm{g}^{-1}$.

\section{Determinação de $\mathrm{Cr}$ (IV) e $\mathrm{Cr}$ (III) nas amostras de sedimento}

A determinação de $\mathrm{Cr}(\mathrm{VI})$ foi feita de acordo com Pettini e Capri. ${ }^{22}$ Adicionou-se a $0,1 \mathrm{~g}$ de solo, $100 \mathrm{~mL}$ de $\mathrm{Na}_{2} \mathrm{CO}_{3}$ 0,28 M e $\mathrm{NaOH} 0,5 \mathrm{~mol} \mathrm{~L}^{-1}, 0,8 \mathrm{~g}$ de $\mathrm{MgCl}_{2}$, sob aquecimento a $90{ }^{\circ} \mathrm{C}$ por 1 h. Filtrou-se e tratou-se a solução com resina XAD 7 a pH 3,0. Posteriormente fez-se a determinação utilizando-se o método espectrofotométrico da 1,5- difenilcarbazida (DPC). O $\mathrm{Cr}$ (III) foi obtido por diferença entre o crômio total e o $\mathrm{Cr}(\mathrm{IV})$.

\section{RESULTADOS E DISCUSSÃO}

Os riscos provocados pelo descarte indiscriminado de resíduos contendo metais potencialmente tóxicos ao solo estão associados principalmente ao transporte desses poluentes no ambiente. Dependendo do método empregado na curtição do couro, o resíduo gerado pode apresentar elevadas concentrações de crômio. Os impactos causados pelo descarte indiscriminado destes resíduos devem ser investigados para prevenir e/ou remediar a contaminação de matrizes ambientais. ${ }^{2-4}$

A Tabela 2 mostra os resultados das concentrações totais de crômio ( $\mathrm{mg} \mathrm{kg}^{-1}$ de solo) nas amostras de solos coletadas em função da profundidade em locais com cultivo de cana-de-açúcar, manga e em cultivo de mandioca (testemunho). Os teores de matéria orgânica (MO) dos solos coletados estão descritos na Tabela 3.

O intervalo obtido para a concentração de crômio total em cultivo de cana foi de 30,93-55,85 mg kg-1, semelhante ao determinado nas amostras testemunho $35,45-53,89 \mathrm{mg} \mathrm{kg}^{-1}$ que indica o teor de crômio dos solos da região. De acordo com valores orientadores proposto pela CETESB $^{13}$ (Tabela 1), a concentração de crômio como padrão de qualidade para solos é de $40 \mathrm{mg} \mathrm{kg}^{-1}$. Como o valor de prevenção é de 75 $\mathrm{mg} \mathrm{kg}^{-1}$ (Tabela 1), considera-se que estes solos não estão impactados. Entretanto, o intervalo obtido para as amostras coletadas no cultivo de manga foi de 40,2-567,2 $\mathrm{mg} \mathrm{kg}^{-1}$. Estes resultados mostram que algumas amostras estão com teores acima do valor de intervenção agrícola para o crômio, $150 \mathrm{mg} \mathrm{kg}^{-1}$ (concentração de determinada substância no solo ou na água subterrânea acima da qual existem riscos potenciais, diretos ou indiretos, à saúde humana, considerado um cenário de exposição genérico). ${ }^{13}$ Além disso, estes resultados mostram que o tipo de manejo influencia no tempo de retenção do metal no solo. Ou seja, em solo onde há maior revolvimento da terra, como é o caso do cultivo de cana, ocorreu decomposição das aparas mais rapidamente e com isso o metal retido no solo fora lixiviado, explicando as menores concentrações determinadas nas amostras de cana-de-açúcar. Nestas amostras, verifica-se ainda lixiviação vertical do crômio, o que não ocorre em cultura perene (manga), o que está diretamente relacionado com o tipo de manejo realizado. 
Tabela 2. Resultados das concentrações totais de crômio ( $\mathrm{mg} \mathrm{kg}^{-1}$ de solo) em amostras de solos coletadas em função da profundidade em locais com cultivo de cana-de-açúcar, manga e o testemunho em cultivo de mandioca

\begin{tabular}{|c|c|c|c|c|c|c|c|c|c|}
\hline \multirow[t]{2}{*}{$\begin{array}{l}\text { Profundidade } \\
(\mathrm{cm})\end{array}$} & \multicolumn{3}{|c|}{$\begin{array}{l}\text { Cultivo de cana } \\
\text { Concentração de crômio total } \\
\left(\mathrm{mg} \mathrm{kg}^{-1} \text { de solo }\right)\end{array}$} & \multicolumn{3}{|c|}{$\begin{array}{l}\text { Cultivo de manga } \\
\text { Concentração de crômio total } \\
\left(\mathrm{mg} \mathrm{kg}^{-1} \text { de solo }\right)\end{array}$} & \multicolumn{3}{|c|}{$\begin{array}{c}\text { Testemunha } \\
\text { Concentração de crômio total } \\
\left(\mathrm{mg} \mathrm{kg}^{-1} \text { de solo }\right)\end{array}$} \\
\hline & A & B & $\mathrm{C}$ & A & B & $\mathrm{C}$ & A & $\mathrm{B}$ & $\mathrm{C}$ \\
\hline-5 & $30,9 \pm 0,2$ & $38,7 \pm 0,2$ & $26,8 \pm 0,5$ & $40,2 \cdot 10^{1} \pm 0,4$ & $23,5 \cdot 10^{1} \pm 0,2$ & $38,2 \pm 0,3$ & $56,7 \pm 0,2$ & $47,5 \pm 0,3$ & $41,8 \pm 0,2$ \\
\hline $5-10$ & $33,0 \pm 0,3$ & $51,3 \pm 0,3$ & $35,1 \pm 0,4$ & $56,7 \cdot 10^{1} \pm 0,3$ & $12,5 \cdot 10^{1} \pm 0,2$ & $51,2 \pm 0,2$ & $35,9 \pm 0,4$ & $47,7 \pm 0,5$ & $37,4 \pm 0,4$ \\
\hline $10-20$ & $32,2 \pm 0,2$ & $36,4 \pm 0,4$ & $40,4 \pm 0,2$ & $11,2 \cdot 10^{1} \pm 0,3$ & $43,9 \pm 0,6$ & $51,4 \pm 0,2$ & $35,5 \pm 0,4$ & $38,2 \pm 0,3$ & $41,8 \pm 0,5$ \\
\hline $20-40$ & $37,2 \pm 0,1$ & $37,8 \pm 0,3$ & $44,9 \pm 0,3$ & $57,7 \pm 0,2$ & $40,3 \pm 0,3$ & $40,2 \pm 0,4$ & $36,4 \pm 0,2$ & $38,3 \pm 0,4$ & $50,2 \pm 0,6$ \\
\hline $10-60$ & $49,1 \pm 0,3$ & $40,7 \pm 0,2$ & $55,9 \pm 0,4$ & $79,3 \pm 0,2$ & $47,00 \pm 0,2$ & $47,5 \pm 0,5$ & $42,6 \pm 0,5$ & $58,9 \pm 0,5$ & $53,9 \pm 0,3$ \\
\hline 100 & $38,8 \pm 0,4$ & $35,8 \pm 0,3$ & $36,4 \pm 0,3$ & $43,8 \pm 0,4$ & $462,5 \pm 0,4$ & $62,3 \pm 0,6$ & $38,8 \pm 0,4$ & $44,5 \pm 0,6$ & $37,8 \pm 0,4$ \\
\hline
\end{tabular}

Valor certificado do material de referência: $130 \pm 4 \mathrm{mg} \mathrm{kg}^{-1}$. Valor determinado: $129 \pm 0,5 \mathrm{mg} \mathrm{kg}^{-1}$

Tabela 3. Resultados dos teores de matéria orgânica (\%) determinados em amostras de solos coletadas em função da profundidade em locais com cultivo de cana-de-açúcar, manga e o testemunho em cultivo de mandioca

\begin{tabular}{lccccccccc}
\hline Profundidade $(\mathrm{cm})$ & \multicolumn{1}{c}{ Cultivo de cana Matéria orgânica $(\%)$} & \multicolumn{3}{c}{ Cultivo de manga } & \multicolumn{3}{c}{ Testemunha } \\
\hline & A & B & C & A & B & C & A & B & C \\
$0-5$ & 1,2 & 1,9 & 1,4 & 1,9 & 2,0 & 2,5 & 1,6 & 1,8 & 1,7 \\
$5-10$ & 1,2 & 1,7 & 1,5 & 2,1 & 1,7 & 1,9 & 1,6 & 1,6 & 1,6 \\
$10-20$ & 1,0 & 1,5 & 1,3 & 1,5 & 1,7 & 3,0 & 1,2 & 1,2 & 1,4 \\
$20-40$ & 0,9 & 1,2 & 1,1 & 1,1 & 1,4 & 1,4 & 1,0 & 1,1 & 1,1 \\
$40-60$ & 0,9 & 1,0 & 1,0 & 0,9 & 1,1 & 1,0 & 0,8 & 1,0 & 1,0 \\
100 & 1,1 & 0,9 & 0,9 & 0,8 & 0,8 & 0,8 & 0,8 & 1,0 & 0,8 \\
\hline
\end{tabular}

Os resultados para as concentrações de crômio biodisponível foram inferiores ao limite de detecção do método $\left(0,01 \mathrm{mg} \mathrm{kg}^{-1}\right)$, indicando que todo crômio presente nas amostras está complexado ou na forma insolúvel. Complexos metal-matéria orgânica de solo podem também ocorrer com argilo-minerais, que estão recobertos com óxidos metálicos tais como ferro e alumínio. Argilas tendem a estabilizar a matéria orgânica do solo e uma correlação é sempre observada entre o conteúdo de argila e a matéria orgânica do solo. Os tipos de interações envolvidas nos complexos argilas-matéria orgânica de solo incluem adsorção física ou interações por forças de van der Waals e eletrostáticas, ligações envolvendo espécies metálicas pela qual o metal polivalente forma uma ponte entre a molécula orgânica e a superfície inorgânica (argila mineral-metal-MO), adsorção química e ligação de hidrogênio. Dois ou mais destes mecanismos podem ocorrer simultaneamente dependendo do tipo de matéria orgânica, da natureza do íon trocável na superfície da argila, da acidez superficial e do conteúdo da mistura do sistema. ${ }^{23}$

Os teores de matéria orgânica determinados nas amostras de solos estão de acordo com o tipo de solo da região. ${ }^{18}$ Os resultados dos teores de MO (Tabela 3) mostram que, de maneira geral, o teor de MO diminui com o aumento da profundidade e não foi possível estabelecer relação direta entre o teor de matéria orgânica e a concentração de crômio estudada. Isso possivelmente está relacionado com a falta de homogeneidade da distribuição das aparas de couro e no local onde há cultivo de manga, em que não ocorre praticamente revolvimento da terra, a decomposição do material é mais lenta que na cana-de-açúcar, por exemplo. É importante ressaltar que as aparas foram descartadas em 2001, isto é, já se passaram 6 anos e ainda há elevadas concentrações de $\mathrm{Cr}$ no solo nas amostras de cultivo de manga.

De acordo com Han et al. ${ }^{2}$ que investigaram a distribuição, transformação e biodisponibilidade de crômio trivalente e hexavalente em solos contaminados, a maior porcentagem de $\mathrm{Cr}$ determinado estava na fração ligada à matéria orgânica (55-85\%). Isto implica que a matéria orgânica exerce importante função na ligação de $\mathrm{Cr}$ em solos. Como nas amostras estudadas, o crômio não está na forma biodisponível, pode-se inferir que o metal determinado está retido na matéria orgânica e/ou fração mineral do solo.

Os resultados da concentração de crômio total ( $\mathrm{mg} \mathrm{kg}^{-1}$ de solo), determinados nas amostras coletadas na superfície (Tabela 4), confirmaram a heterogeneidade das amostras coletadas no cultivo de manga. Valores muito semelhantes aos de referência de qualidade da CETESB foram obtidos para as amostras oriundas do cultivo de cana, devido à influência do manejo de solo, como discutido anteriormente. Estes resultados mostram a dificuldade de se monitorar áreas impactadas por fonte difusas, como são as áreas agrícolas.

Os resultados da análise de água superficial (Tabela 5) foram inferiores ao limite de detecção $\left(0,01 \mathrm{mg} \mathrm{L}^{-1}\right)$ de $\mathrm{Cr}(\mathrm{III})$ e $\mathrm{Cr}(\mathrm{VI})$ indicando que o crômio determinado no solo está retido na $\mathrm{MO}$ e/ ou fração mineral resultando em baixa mobilidade deste metal para o sistema aquático.

Os resultados das análises de sedimentos indicaram maiores teores a jusante do que a montante (Tabela 5). As várias abordagens descritas na literatura, empregadas na avaliação da qualidade e manejo de sedimentos contaminados, fazem uso de valores guias de qualidade de sedimentos. ${ }^{16}$ Para crômio os valores de nível limiar de efeitos (TEL) e nível provável de efeitos (PEL) são, respectivamente, 37,3 e 90,0 mg kg-1 . ${ }^{16}$ Assim, mesmo que os valores das concentrações de crômio a jusante estejam mais elevados que a montante, ambos estão abaixo do nível limiar de efeitos. Estes valores, inferiores ao TEL e ao PEL nas amostras de sedimentos, estão relacionados com a capacidade da matéria orgânica e fração mineral em reter metais, isto é, com estes resultados, pode-se inferir que a mobilidade do crômio para águas e sedimento é baixa. 
Tabela 4. Resultados das concentrações totais de crômio (mg kg-1 de solo) em amostras de solos coletadas na superfície $(0-5 \mathrm{~cm})$ em locais com cultivo de cana e manga

\begin{tabular}{lcc}
\hline $\begin{array}{l}\text { Cultivo de cana } \\
\begin{array}{l}\text { Concentração de } \\
\text { crômio total } \\
\left(\mathrm{mg} \mathrm{kg}^{-1} \text { de solo) }\right.\end{array}\end{array}$ & $\begin{array}{c}\text { Cultivo de manga } \\
\text { Concentração de } \\
\text { crômio total } \\
\left(\mathrm{mg} \mathrm{kg}^{-1} \text { de solo) }\right.\end{array}$ & $\begin{array}{c}\text { Testemunha } \\
\text { Concentração de } \\
\text { crômio total } \\
\left(\mathrm{mg} \mathrm{kg}^{-1} \text { de solo }\right)\end{array}$ \\
\hline $35,9 \pm 0,2$ & $39,3 \pm 0,6$ & $39,2 \pm 0,4$ \\
$37,8 \pm 0,3$ & $60,3 \pm 0,2$ & $32,2 \pm 0,3$ \\
$32,6 \pm 0,4$ & $540,6 \pm 0,4$ & $54,8 \pm 0,5$ \\
$32,7 \pm 0,2$ & $37,6 \pm 0,3$ & $38,7 \pm 0,3$ \\
$36,2 \pm 0,3$ & $33,9 \pm 0,5$ & $35,2 \pm 0,2$ \\
$31,2 \pm 0,5$ & $149,5 \pm 0,4$ & $37,1 \pm 0,4$ \\
$35,3 \pm 0,3$ & $57,8 \pm 0,3$ & $37,6 \pm 0,3$ \\
$33,2 \pm 0,2$ & $42,9 \pm 0,2$ & $35,5 \pm 0,2$ \\
$38,1 \pm 0,4$ & $112,1 \pm 0,4$ & $34,9 \pm 0,5$ \\
$30,9 \pm 0,2$ & $62,9 \pm 0,2$ & $42,2 \pm 0,3$ \\
\hline
\end{tabular}

Tabela 5. Resultados das concentrações de Cr(III), Cr(VI) em amostras de águas e em amostras de sedimentos

\begin{tabular}{lcccc}
\hline Local de coleta & $\begin{array}{c}\text { Sedimento } \\
\mathrm{mg} \mathrm{kg}^{-1} \\
\mathrm{Cr}(\mathrm{III})\end{array}$ & $\begin{array}{c}\text { Água } \\
\mathrm{mg} \mathrm{L}^{-1}\end{array}$ & $\begin{array}{c}\text { Sedimento } \\
\mathrm{mg} \mathrm{kg}^{-1} \\
\mathrm{Cr}(\mathrm{VI})\end{array}$ & $\begin{array}{c}\text { Água } \\
\mathrm{mg} \mathrm{L}^{-1}\end{array}$ \\
\hline Jusante & 32,51 & $<0,05$ & $<0,05$ & $<0,01$ \\
Montante & 10,60 & $<0,05$ & $<0,05$ & $<0,01$ \\
\hline
\end{tabular}

Valor certificado do material de referência para sedimento:

$40,9 \pm 1,9 \mathrm{mg} \mathrm{kg}^{-1}$. Valor determinado: $39,5 \pm 0,5 \mathrm{mg} \mathrm{kg}^{-1}$

\section{CONCLUSÕES}

Os resultados da avaliação da contaminação de solo por deposição de resíduos oriundos de curtume contendo crômio sugerem que, na região amostrada, nos cultivos de cana-de-açúcar o solo não está impactado (resultados da ordem de referência de qualidade estabelecidos pela legislação nacional), devido ao tipo de manejo nesta cultura. Os teores de crômio determinados nas amostras de solos coletadas em cultivo de manga indicaram heterogeneidade nos resultados, isto é, $22,2 \%$ das concentrações determinadas estão na ordem de intervenção e 38,9\% na ordem de prevenção. Entretanto, os níveis de metal biodisponível indicaram que o crômio, presente nas amostras de solos, está retido na matéria orgânica e/ou na fração mineral do solo.

As amostras de solos coletadas na superfície dos diferentes cultivos indicam heterogeneidade na distribuição de crômio, caracterizando dificuldade em monitar estas áreas agrícolas.
Os teores de $\mathrm{Cr}(\mathrm{III})$ e $\mathrm{Cr}(\mathrm{VI})$ determinados em amostras de água e sedimento indicaram baixa mobilidade do $\mathrm{Cr}$ presente no solo para estas matrizes. Isto pode ser explicado devido à ação da matéria orgânica e da fração mineral como complexante de crômio presente no solo, influenciando no transporte e biodisponibilidade para o sistema aquático.

\section{REFERÊNCIAS}

1. Alcantâra, M. A. K.; Camargo, O. A.; Rev. Bras. Eng. Agric. Ambient. 2001, 5, 497.

2. Han, F. X.; Su, Y.; Sridhar, M. B. B.; Monts, D. L.; Plant soil 2004, 265, 243.

3. Jordão, C. P.; Silva, A. C.; Pereira, J. L.; Brune, W.; Quim. Nova 1999, $22,48$.

4. Silva, C. S.; Pedrozo, M. F.; Cadernos de Referência Ambiental, $1^{\text {a }}$ ed., Centro de recursos ambientais: Salvador, 2001.

5. Proctor, D. M.; Finley, B. L.; Harris, M. A.; Paustenbach, D.; Rabbe, D.; J. Soil Cont. 1997, 6, 569.

6. Appenroth, K. J.; Bischoff, M.; Gabrys H.; Stoeckel J.; Swartz, H. M.; Walczak, T.; Winnefeld, K.; J. Inorg. Biochem. 2000, 78, 235.

7. Ferreira, A. S.; Camargo, F. A. O.; Tedesco, M. J.; Bissani, C. A.; Rev. Bras. Ciência do Solo 2003, 27, 755.

8. Castilhos, D. D.; Costa, C. N.; Passianoto, C. C.; Lima, A. C. R.; Lima, C. L. R.; Muller, V.; Cienc. Rural 2001, 31, 969.

9. Avudainayagam, S.; Megharaj, M.; Owens, G.; Kookana, R. S.; Chittleborough, D.; Naidu, R.; Rev. Environ. Cont. Toxicol. 2003, 178, 53.

10. Passianoto, C. C.; Castilhos, D. D.; Castilhos, R. M. V.; Lima, A. C. R.; Lima, C. L. R.; Rev. Bras. Agrociência 2001, 7, 125.

11. Masscheleyn, P. H.; Pardue, J. H.; DeLaune, R. D.; Patrlck, Jr., W. H.; Environ. Sci. Technol. 1992, 26, 1217.

12. James, B. R.; Bartlett, R. J.; J. Environ. Qual. 1983, 12, 173

13. http://www.cetesb.sp.gov.br/Agua/rios/relatorios.asp, acessada em Julho 2007.

14. Companhia de Tecnologia de Saneamento Ambiental. Informação técnica $n^{\circ}$ 057/05/CEA, 2003.

15. Relatório de análise CENA/USP, 2002.

16. Mozeto, A. A.; Umbuzeiro, G. A.; Jardim, W. F.; Métodos de coleta, análises físico-químicas e ensaios biológicos e ecotoxicológicos de sedimentos de água doce, $1^{a}$ ed., Cubo: São Carlos, 2006.

17. van Raij, B.; Andrade, J. C.; Cantarella, H.; Quaggio, J. A.; Análise química para avaliação da fertilidade de solos tropicais, $1^{\text {a }}$ ed., Instituto Agronômico: Campinas, 2001.

18. Santos, A.; Tese de Doutorado, Universidade de São Paulo, Brasil, 2003.

19. Bevilacqua, J. E.; Tese de Doutorado, Universidade de São Paulo, Brasil, $1996 .$.

20. Rocha, J. C.; Barbiéri, R. S.; Cardoso, A. A.; Quim. Nova 1990, 13, 200.

21. Andrade, J. C.; Rocha, J. C.; Baccan, N.; Analyst 1985, 110, 197.

22. Pettine, M.; Capri, S.; Anal. Chim. Acta 2005, 540, 239.

23. Sparks, D. L.; Environmental soil chemistry, $1^{\text {st }}$ ed., Academic Press: San Diego, 1995. 